\title{
DESENVOLVIMENTO NINFAL DE MYZUS PERSICAE (SULZER, 1776) \\ (HEMIPTERA: APHIDIDAE) SOBRE BERINJELA EM \\ DIFERENTES TEMPERATURAS ${ }^{(1)}$
}

\author{
NORTON RODRIGUES CHAGAS FILHO ${ }^{(2)}$; MARCOS DONISETI MICHELOTTO ${ }^{(2)}$; \\ RICARDO ADAIME DA SILVA ${ }^{(3)}$; ANTONIO CARLOS BUSOLI ${ }^{(4)}$
}

\begin{abstract}
RESUMO
Este trabalho teve como objetivo avaliar o efeito de diferentes temperaturas no desenvolvimento ninfal de Myzus persicae sobre folhas de berinjela (Solanum melongena). O experimento foi desenvolvido em câmaras climatizadas, sob condições controladas de temperatura de 15, 20, 25 e $30 \pm 1{ }^{\circ} \mathrm{C}$, umidade relativa do ar de $70 \% \pm 10 \%$ e fotofase de 12 horas. A biologia de $M$. persicae foi acompanhada sobre discos foliares de berinjela ( $3 \mathrm{~cm}$ de diâmetro) mantidos em placas de Petri contendo solução ágar-água a $1 \%$ geleificada. Foram estimadas as curvas mais ajustadas à duração dos estádios ninfais de M. persicae, suas equações de regressão e os respectivos coeficientes de determinação $\left(R^{2}\right)$. O número de estádios ninfais foi afetado pela temperatura; a 15 e $20{ }^{\circ} \mathrm{C}$, respectivamente, em $30,4 \%$ e 4,2\% das ninfas observouse um estádio adicional. Afídeos mantidos a $30{ }^{\circ} \mathrm{C}$ apresentaram a menor viabilidade na fase ninfal $(8 \%)$. A duração da fase ninfal foi de 9,$4 ; 7,6 ; 5,9$ e 7,0 dias, respectivamente, a 15, 20, 25 e $30^{\circ} \mathrm{C}$. As temperaturas de 15 e $20{ }^{\circ} \mathrm{C}$ foram as mais favoráveis para o desenvolvimento ninfal de $M$. persicae sobre discos de folha de berinjela.
\end{abstract}

Palavras-chaves: Solanum melongena, afídeo-da-batatinha, biologia.

\section{ABSTRACT \\ NYMPHAL DEVELOPMENT OF MYZUS PERSICAE (SULZER, 1776) (HEMIPTERA: APHIDIDAE) ON EGGPLANT AT DIFFERENT TEMPERATURES}

The objective of this work was to study the nymphal development of Myzus persicae on leaves of eggplant (Solanum melongena) at four constant temperatures. The experiment was carried out in the biocontrol laboratory, with the following controlled conditions: temperatures $\left(15,20,25\right.$ and $\left.30{ }^{\circ} \mathrm{C} \pm 1{ }^{\circ} \mathrm{C}\right)$; relative humidity $(70 \% \pm 10 \%)$, and photophase (12 hours). The biology of $M$. persicae was followed on leaf discs (3 cm diameter) kept in Petri dishes containing a layer of agar-water (1\%). It was evaluated the best fitted curve to the biological aspects of $M$. persicae, as well as their regression equations and respective determination coefficients $\left(\mathrm{R}^{2}\right)$. The number of nymphal stage was affected by temperature: 15 and $20{ }^{\circ} \mathrm{C}$, resulted in $30.4 \%$ and $4.2 \%$ of nymphs showing an $5^{\text {th }}$ nymphal stage, respectively. At $15,20,25$ and 30 ${ }^{\circ} \mathrm{C}$, nymphal phase lasted for 9.4; 7.6; 5.9 and 7.0 days, respectively. Temperatures of 15 and $20{ }^{\circ} \mathrm{C}$ were more favorable to nymphal development of $M$. persicae on leaf discs of eggplant.

Key words: Solanum melongena, green peach aphid, biology.

(1) Recebido para publicação em 4 de junho de 2004 e aceito em 14 de março de 2005.

${ }^{2}$ ) Aluno do Programa de Pós-graduação em Entomologia Agrícola da Faculdade de Ciências Agrárias e Veterinárias da Universidade Estadual Paulista (FCAV/UNESP), Via de Acesso Prof. Paulo Donato Castellane, s/n, 14884-900 Jaboticabal, São Paulo, Brasil. Bolsista CAPES. E-mail: nortonrc@fcav.unesp.br; mdmichelotto@yahoo.com.br.

${ }^{3}$ ) Embrapa Amapá, Rodovia JK, km 5, 68903-000 Macapá, Amapá, Brasil. E-mail: ricardoadaime@yahoo.com.br

(4) Departamento de Fitossanidade da Faculdade de Ciências Agrárias e Veterinárias da Universidade Estadual Paulista (FCAV/UNESP). E-mail: acbusoli@fcav.unesp.br 


\section{INTRODUÇÃO}

A berinjela (Solanum melongena L.) (Solanaceae), originária do Continente Asiático, é uma planta de hábito perene, porém cultivada como anual (Filgueira, 2002). No Estado de São Paulo, ocupa uma área de 1.037 hectares, produzindo 47.549 toneladas e gerando 1.023 empregos diretos, tendo Campinas, Aguaí, São José do Rio Pardo e Monte Alto, como principais municípios produtores (CEASA, 2004).

De acordo com Blackman e EAstop (1984), os afídeos (Hemiptera: Aphididae) associados à cultura da berinjela são Aphis fabae, Aphis gossypii, Aulacorthum solani, Macrosiphum euphorbiae e Myzus persicae. No Brasil, M. persicae é relatado como praga na cultura, destacando-se por danificar direta e indiretamente as plantas de berinjela (PINTO et al., 2000). É o mais eficiente vetor do Potato Virus Y (PVY) pertencente ao gênero Potyvirus, que causa severos danos à cultura da berinjela, reduzindo drasticamente a produtividade na maioria das cultivares (PINTO et al., 2000). Os autores ainda relatam que as plantas infectadas por PVY apresentam folhas com sintomas de mosaico, amarelecimento e redução de tamanho, além de frutos pouco desenvolvidos.

M. persicae é uma espécie polífaga, cosmopolita e pode transmitir mais de 100 vírus em diversas culturas (RADCLIFFE, 1982; BLACKMAN e EASTOP, 1984). Na cultura da batata, é considerado como o mais importante vetor de Popato Leafroll Virus (PLRV) e PVY. Além da transmissão dos vírus, altas populações de $M$. persicae podem ocasionar perdas até de $54 \%$ da massa seca de plantas de batata, decorrentes da ação toxicogênica da saliva, a qual ocasiona necroses, principalmente ao longo das nervuras (ILHARCO, 1992).

Dentre os fatores que podem influenciar a bioecologia dos afídeos destaca-se a temperatura. Segundo EAstop (1977), a temperatura influi no tamanho das populações, na maturação das fêmeas, na taxa de reprodução, longevidade e dispersão. Dada a importância de $M$. persicae na cultura da berinjela e da possibilidade de transmitir vírus à cultura e a outras olerícolas, o objetivo deste trabalho foi estudar o desenvolvimento ninfal de $M$. persicae em laboratório, sob efeito de quatro temperaturas constantes $\left(15,20,25\right.$ e $\left.30{ }^{\circ} \mathrm{C}\right)$ tendo como substrato folhas de plantas de berinjela.

\section{MATERIAL E MÉTODOS}

O experimento foi desenvolvido no Laboratório de Controle Biológico de Insetos do
Departamento de Fitossanidade, setor de Entomologia da FCAV-UNESP em Jaboticabal (SP). Para a criação de manutenção e o estudo do desenvolvimento dos estádios ninfais de M. persicae foram utilizadas quatro câmaras climatizadas reguladas nas temperaturas de $15,20,25$ e $30^{\circ} \mathrm{C} \pm 1^{\circ} \mathrm{C}$, umidade relativa do ar de $70 \%$ $\pm 10 \%$ e fotofase de 12 horas.

As sementes de berinjela (cultivar Nápoli) foram semeadas em vasos de polietileno com capacidade para 5 litros, contendo terra, areia e esterco na proporção 2:1:1 e mantidos em gaiolas de 1,5 x 1,5 $m$ revestidas com uma tela anti-afídeo. Os afídeos utilizados no experimento foram coletados em colônias presentes em plantas de berinjela no campo, e transferidos para plantas de 50 dias de idade com auxílio de um pincel, para a criação no laboratório.

As folhas de berinjela utilizadas no ensaio foram previamente lavadas em água corrente e deixadas imersas em solução de hipoclorito de sódio a $1 \%$ por um minuto. Após a assepsia, as folhas foram secas em papel absorvente e, utilizando-se um vazador, foram obtidos os discos foliares. Para obtenção de adultos na fase reprodutiva, foram coletadas folhas de berinjela contendo afídeos provenientes das colônias de criação de manutenção, e levados até o laboratório. Para cada temperatura (15, 20,25 e $30^{\circ} \mathrm{C}$ ) foram preparados três recipientes, destinados à criação dos adultos, que consistiram de placas de Petri (6 cm de diâmetro) contendo $15 \mathrm{~mL}$ de solução geleificada de ágar-água (1\%) e um disco de folha de berinjela de $3 \mathrm{~cm}$ de diâmetro disposto no centro da placa. Em cada disco foram colocados, com auxílio de um pincel, cinco adultos ápteros de $M$. persicae. A tampa dessas placas continha uma abertura de $3 \mathrm{~cm}$ de diâmetro, coberta com uma tela anti-afídeo para permitir a aeração e evitar a fuga dos insetos. As placas foram identificadas e mantidas nas câmaras climatizadas. Foram realizadas três vistorias por dia para a obtenção das ninfas utilizadas no experimento.

Cada unidade experimental foi composta de uma placa de Petri contendo um disco foliar, com a face abaxial voltada para cima, fixo no centro da placa sobre $10 \mathrm{~mL}$ de solução ágar-água. Apenas uma ninfa recém-nascida foi transferida por disco foliar. As avaliações foram realizadas a cada 12 horas, observando-se o número de estádios, a duração de cada estádio e da fase ninfal, assim como a viabilidade de cada estádio e da fase ninfal. Quando foram observados os primeiros sinais de deterioração do disco foliar, a ninfa foi transferida para uma nova unidade experimental contendo novo disco foliar.

Os dados relativos à duração de cada estádio e da fase ninfal foram submetidos à análise de variância (Teste $\mathrm{F}$ ) e as médias dos tratamentos 
comparadas pelo teste de Tukey. Foram também estimadas as curvas mais ajustadas ao desenvolvimento, suas equações de regressão e os respectivos coeficientes de determinação $\left(R^{2}\right)$. Para comparar a viabilidade dos estádios ninfais e da fase ninfal foi utilizado o teste Qui-Quadrado $\left(\chi^{2}\right)$. O nível de significância dos testes foi de $\alpha=5 \%$.

\section{RESULTADOS E DISCUSSÃO}

A temperatura influenciou significativamente no desenvolvimento e na viabilidade ninfal de $M$. persicae (Tabelas 1, 2). Para o intervalo de temperaturas estudadas, em $30,4 \%$ e $4,2 \%$ das ninfas que completaram a fase ninfal observou-se um $5 .^{\circ}$ estádio, nas temperaturas de 15 e $20{ }^{\circ} \mathrm{C}$ respectivamente (Tabela 1). Nas demais ninfas, mantidas a 15 e $20^{\circ} \mathrm{C}$, observaram-se quatro estádios, assim como naquelas mantidas a 25 e $30^{\circ} \mathrm{C}$, concordando com os resultados de Dixon (1987).

A temperatura também influenciou na duração dos estádios ninfais de M. persicae (Tabela 1). A duração do $1 .^{\circ}$ estádio foi menor a $30^{\circ} \mathrm{C}(1,22$ dia $)$ e maior a $15{ }^{\circ} \mathrm{C}(1,82 \mathrm{dia})$ e $20{ }^{\circ} \mathrm{C}$ ( 1,83 dia). Esses resultados são semelhantes aos de NARVÁEz e Notz (1993) que observaram duração média de 1,5 dia para ninfas dessa espécie mantidas sobre folhas de batata, sob temperatura média de $26,71 \pm 3,02{ }^{\circ} \mathrm{C}$. Por outro lado, Cividanes e Souza (2003) obtiveram resultados superiores, variando de 3,1 a 4,3 dias para as temperaturas de $23^{\circ} \mathrm{C}$ e $15^{\circ} \mathrm{C}$, respectivamente, sobre folhas de couve. A curva mais ajustada para a regressão entre as temperaturas e a duração do $1^{\circ}$ estádio foi a polinomial de $1 .^{\circ}$ grau. A duração do $1 .^{\circ}$ estádio foi dependente da temperatura, visto que o aumento implica redução na duração do estádio (Figura 1A).

No $2 .^{\circ}$ estádio ninfal, observou-se que as temperaturas de 15 e $20^{\circ} \mathrm{C}$ proporcionaram as maiores durações, sendo de 2,01 e 1,72 dias respectivamente. Já as menores durações foram observadas a 25 e 30 ${ }^{\circ} \mathrm{C}$ com 1,28 e 1,23 dia respectivamente (Tabela 1). A curva mais ajustada para a regressão entre as temperaturas e a duração do $2 .^{\circ}$ estádio do afídeo foi a polinomial de $1 .^{\circ}$ grau (Figura 1B). Em trabalhos realizados por TAMAKI et al. (1982) e CiviDANES e SOUZA (2003) o aumento da temperatura também diminuiu o tempo de duração do $2 .^{\circ}$ estádio de M. persicae.

Uma redução na duração do $3 .^{\circ}$ estádio ninfal em função da temperatura também foi observada. A maior duração (2,24 dias) ocorreu em ninfas mantidas a $15^{\circ} \mathrm{C}$. As menores durações foram observadas nas ninfas mantidas a 25 e $30{ }^{\circ} \mathrm{C}, 1,31$ e 1,27 dia respectivamente (Tabela 1). TAMAKI et al. (1982), ao estudarem $M$. persicae sobre plantas de batata em diferentes temperaturas, observaram duração de 1,6 dia para o $3 .^{\circ}$ estádio a $20^{\circ} \mathrm{C}$. Cividanes e Souza (2003) observaram variações de $1,1\left(25^{\circ} \mathrm{C}\right)$ a 2,3 dias $\left(15^{\circ} \mathrm{C}\right)$. A curva mais ajustada para a regressão entre as temperaturas e o $3 .^{\circ}$ estádio foi a polinomial de $2 .^{\circ}$ grau; nota-se que a duração desse estádio diminui bastante quando se aumenta a temperatura de 15 para $25{ }^{\circ} \mathrm{C}$, mas diminui pouco de 25 para $30{ }^{\circ} \mathrm{C}$ (Figura 1C).

Durante o $4 .^{\circ}$ estádio ninfal, ocorreu duração significativamente menor (1,59 dias) nas ninfas mantidas na temperatura de $25{ }^{\circ} \mathrm{C}$ do que aquelas mantidas a 15 e $30{ }^{\circ} \mathrm{C}(2,49$ e 3,73 dias $)$ respectivamente (Tabela 1). CividANES e SouzA (2003), ao estudarem $M$. persicae sobre folhas de couve, observaram resultados superiores quanto à duração do $4 .^{\circ}$ estádio em diferentes temperaturas, a menor duração foi registrada a $23{ }^{\circ} \mathrm{C}(1,6$ dia $)$ e a maior a 15 ${ }^{\circ} \mathrm{C}$ (3,4 dias). NARVÁEZ e Notz (1993), utilizando folhas de batata em diferentes idades da planta, observaram que no $4 .^{\circ}$ estádio de M. persicae a duração foi de 1,6 dia, à temperatura média de $26,71 \pm 3,02{ }^{\circ} \mathrm{C}$. Nesse estádio, as diferentes temperaturas estudadas influenciaram sobremaneira sua duração. A curva mais ajustada para a regressão entre as temperaturas e a duração do $4 .^{\circ}$ estádio foi a polinomial de $3 .^{\circ}$ grau, visto que o aumento de temperatura de 15 para $25^{\circ} \mathrm{C}$ ocasionou uma diminuição na duração do estádio e que o aumento de 25 para $30^{\circ} \mathrm{C}$ prolongou a duração do estádio (Figura 1D).

As ninfas com um $5 .^{\circ}$ estádio nas temperaturas de 15 e $25{ }^{\circ} \mathrm{C}$ duraram em média 2,56 e 2,56 dias respectivamente (Tabela 1). A duração da fase ninfal foi maior a $15{ }^{\circ} \mathrm{C}\left(9,36\right.$ dias) e menor a $25{ }^{\circ} \mathrm{C}(5,89$ dias) (Tabela 1). Resultados inferiores foram observados por BASTOS et al. (1996) para ninfas de $M$. persicae mantidas a $25{ }^{\circ} \mathrm{C}$, com duração de 5 dias. NARVÁEZ e Notz (1993) obtiveram valores médios para a fase ninfal de 6,0 e 5,4 dias, para ninfas mantidas sobre folhas de batata e folhas de gergelim respectivamente. A curva mais ajustada para a regressão entre as temperaturas e a duração da fase ninfal de $M$. persicae foi a polinomial de $2{ }^{\circ}$ grau. $\mathrm{O}$ aumento da temperatura de 15 para $25^{\circ} \mathrm{C}$ provocou redução da fase ninfal, e o aumento de 25 para $30{ }^{\circ} \mathrm{C}$ prolongou a duração da mesma (Figura 1E). De acordo com WiLsON e BARNETT (1983) considera-se o limite térmico superior de desenvolvimento de um inseto a temperatura na qual a velocidade de seu desenvolvimento começa a diminuir. Assim, o limite térmico superior de $M$. persicae sobre berinjela está na faixa de temperatura de 25 até próximo de $30^{\circ} \mathrm{C}$. 
As diferenças verificadas na duração dos estádios ninfais de $M$. persicae em relação a outros trabalhos podem também estar relacionadas à diferença na planta hospedeira utilizada (WALE et al., 2000) e até mesmo em biótipos diferentes (TAMAKI et al., 1982). EBERT e CARTWRight (1997) relatam ainda que, em um mesmo hospedeiro, diversos autores observaram resultados distintos, em função da variabilidade genética existente, que pode ser influenciada pelas diferenças no procedimento experimental. Segundo esses autores, as diferenças incluem o local onde foi realizada a pesquisa, o tipo de confinamento do afídeo (em discos de folhas, isolamento de toda a planta ou pequenas gaiolas nas folhas) e a idade da colônia do afídeo.

No $1 .^{\circ}$ estádio de M. persicae ocorreu alta viabilidade em todas as temperaturas estudadas, sendo de $100 \%$ para ninfas mantidas a $15{ }^{\circ} \mathrm{C}$ e $96 \%$ para aquelas mantidas nas demais temperaturas estudadas (Tabela 2). No 2. ${ }^{\circ}$ estádio, a temperatura de $20{ }^{\circ} \mathrm{C}$ proporcionou a maior viabilidade $(100 \%)$. No $3 .^{\circ}$ e $4 .^{\circ}$ estádios, em ninfas mantidas a $30{ }^{\circ} \mathrm{C}$ ocorreu menor viabilidade que aquelas mantidas nas demais temperaturas (Tabela 2). As ninfas que passaram pelo $5 .^{\circ}$ estádio apresentaram $100 \%$ de viabilidade (Tabela 2 ).

Tabela 1. Duração média (em dias) dos estádios ninfais e da fase ninfal de Myzus persicae sobre folhas de berinjela em diferentes temperaturas. Jaboticabal (SP), 2003

\begin{tabular}{|c|c|c|c|c|c|c|}
\hline \multirow{2}{*}{ Temperatura } & \multicolumn{5}{|c|}{ Estádios ninfais } & \multirow{2}{*}{ Fase ninfal } \\
\hline & $1 .^{\circ}$ & $2 .^{\circ}$ & $3 .^{\circ}$ & $4 .^{\circ}$ & $5 .^{\circ}$ & \\
\hline $15^{\circ} \mathrm{C}$ & $\begin{array}{c}1,82 \pm 0,14 a \\
(n=25)\end{array}$ & $\begin{array}{c}2,01 \pm 0,12 a \\
(n=23)\end{array}$ & $\begin{array}{c}2,24 \pm 0,06 a \\
(n=23)\end{array}$ & $\begin{array}{c}2,49 \pm 0,15 a b \\
(n=23)\end{array}$ & $\begin{array}{c}2,56 \pm 0,18 \\
(n=7)\end{array}$ & $\begin{array}{c}9,36 \pm 0,17 a \\
(n=23)\end{array}$ \\
\hline $20^{\circ} \mathrm{C}$ & $\begin{array}{c}1,83 \pm 0,09 \quad a \\
(n=24)\end{array}$ & $\begin{array}{c}1,72 \pm 0,07 a \\
(n=24)\end{array}$ & $\begin{array}{c}1,78 \pm 0,06 b \\
(n=24)\end{array}$ & $\begin{array}{c}2,12 \pm 0,50 b c \\
(n=24)\end{array}$ & $\begin{array}{c}2,56 \pm 0,00(n=1) \\
(n=1)\end{array}$ & $\begin{array}{c}7,55 \pm 0,11 \quad b \\
(n=24)\end{array}$ \\
\hline $25^{\circ} \mathrm{C}$ & $\begin{array}{c}1,60 \pm 0,14 a b \\
(n=24)\end{array}$ & $\begin{array}{c}1,28 \pm 0,12 b \\
(n=20)\end{array}$ & $\begin{array}{c}1,31 \pm 0,08 c \\
(n=19)\end{array}$ & $\begin{array}{c}1,59 \pm 0,12 c \\
(n=17)\end{array}$ & $\begin{array}{l}-(1) \\
-\end{array}$ & $\begin{array}{c}5,89 \pm 0,16 \\
(n=17)\end{array}$ \\
\hline $30^{\circ} \mathrm{C}$ & $\begin{array}{c}1,22 \pm 0,06 b \\
(n=24)\end{array}$ & $\begin{array}{c}1,23 \pm 0,90 b \\
(n=17)\end{array}$ & $\begin{array}{c}1,27 \pm 0,17 \quad c \\
(n=8)\end{array}$ & $\begin{array}{c}3,73 \pm 2,04 \mathrm{a}- \\
(\mathrm{n}=2)\end{array}$ & $\begin{array}{l}- \\
-\end{array}$ & $\begin{array}{c}7,00 \pm 2,04 \quad b c \\
(n=2)\end{array}$ \\
\hline Teste F & $6,31^{* *}$ & $12,87^{* *}$ & $32,68 * *$ & $10,53^{* *}$ & - & $67,14^{* *}$ \\
\hline C.V. (\%) & 34,31 & 29,45 & 19,29 & 29,66 & - & 9,98 \\
\hline
\end{tabular}

Média \pm erro padrão. Médias seguidas pela mesma letra na coluna não diferem significativamente entre si pelo teste de Tukey a $5 \%$. $\left({ }^{1}\right)$ Não houve ninfas de $5 .^{\circ}$ estádio nas temperaturas de 25 e $30{ }^{\circ} \mathrm{C}$.

$\mathrm{n}=$ número de repetições.

Tabela 2. Viabilidade dos estádios ninfais e da fase ninfal de Myzus persicae sobre folhas de berinjela em diferentes temperaturas. Jaboticabal (SP), 2003

\begin{tabular}{|c|c|c|c|c|c|c|}
\hline \multirow{2}{*}{ Temperatura } & \multicolumn{5}{|c|}{ Estádios ninfais } & \multirow{2}{*}{ Fase ninfal } \\
\hline & $1 .^{\circ}$ & $2 .^{\circ}$ & $3 .^{\circ}$ & $4 .^{\circ}$ & $5 .^{\circ}$ & \\
\hline $15^{\circ} \mathrm{C}$ & $100,0 \%$ a & $92,0 \% \mathrm{ab}$ & $100,0 \%$ a & $100,0 \%$ a & $100,0 \%$ & $92,0 \%$ a \\
\hline $20^{\circ} \mathrm{C}$ & $96,0 \%$ a & $100,0 \%$ a & $100,0 \%$ a & $100,0 \%$ a & $100,0 \%$ & $96,0 \%$ a \\
\hline $25^{\circ} \mathrm{C}$ & $96,0 \%$ a & $80,0 \%$ b & $95,0 \%$ a & $89,5 \%$ a & - (1) & $68,0 \%$ b \\
\hline $30^{\circ} \mathrm{C}$ & $96,0 \%$ a & $70,8 \%$ b & $47,0 \% \mathrm{~b}$ & $25,0 \% \mathrm{~b}$ & - & $8,0 \% \quad c$ \\
\hline$\chi^{2}$ & $1,03^{\mathrm{ns}}$ & $9,70^{*}$ & $34,56^{* *}$ & $39,88^{* *}$ & - & $55,08^{* *}$ \\
\hline
\end{tabular}

ns: não significativo; ** *: significativo a $1 \%$ e a $5 \%$ de probabilidade respectivamente.

Médias seguidas pela mesma letra na coluna não diferem significativamente entre si pelo teste Qui-Quadrado a 5\% de probabilidade.

${ }^{1}$ ) Não houve ninfas de $5^{\circ}$ estádio nas temperaturas de 25 e $30^{\circ} \mathrm{C}$. 

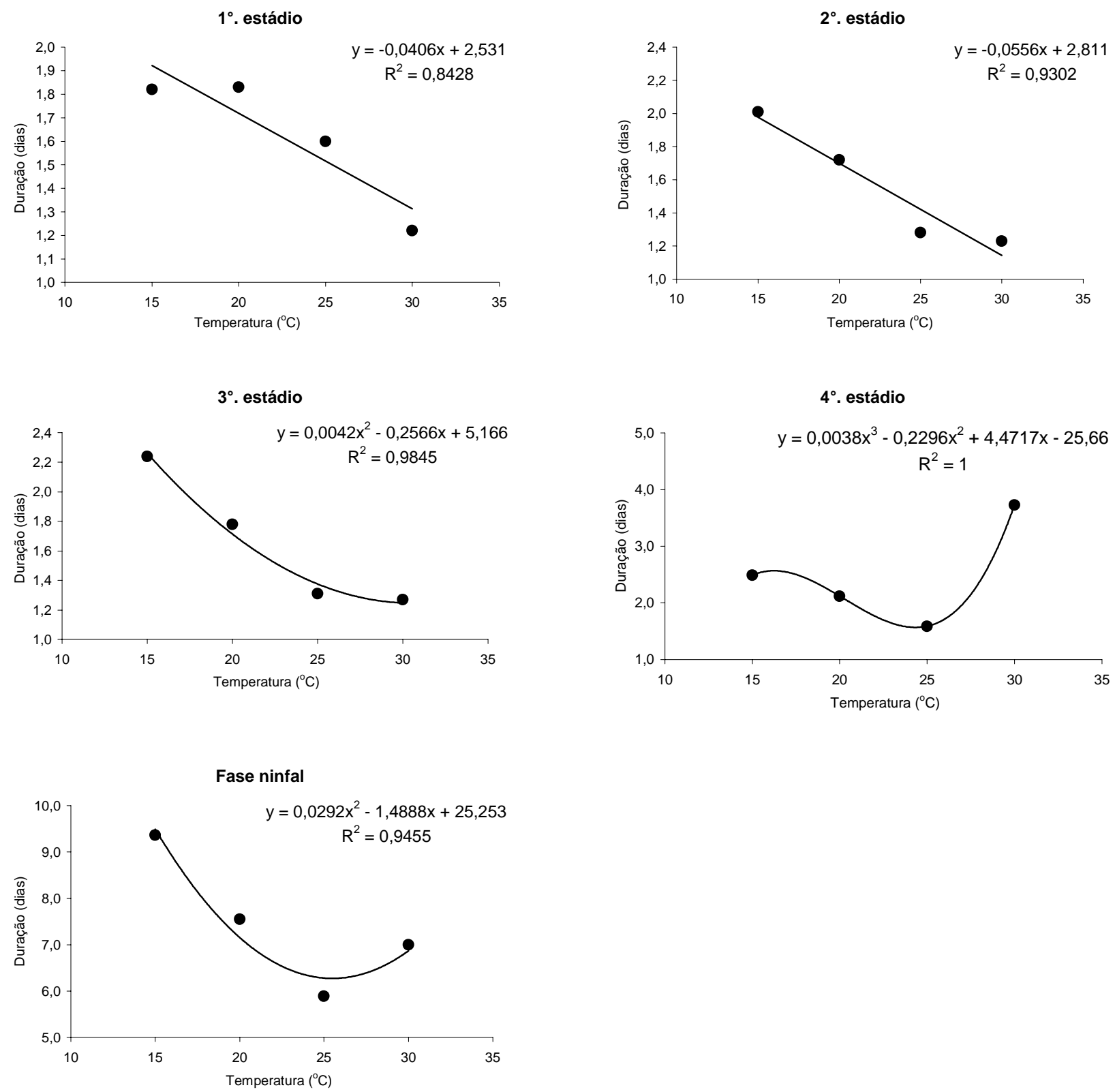

Figura 1. Curva ajustada para a regressão entre a temperatura e a duração do $1 .^{\circ}(\mathrm{A}), 2 .^{\circ}(\mathrm{B}), 3 .^{\circ}(\mathrm{C})$ e $4 .^{\circ}(\mathrm{D})$ estádios ninfais e a fase ninfal (E) de Myzus persicae sobre folhas de berinjela. Jaboticabal (SP), 2003.

A viabilidade da fase ninfal foi maior em ninfas mantidas a 15 e $20{ }^{\circ} \mathrm{C}$, em relação às ninfas mantidas a 25 e $30{ }^{\circ} \mathrm{C}$. Em ninfas mantidas a $30{ }^{\circ} \mathrm{C}$ ocorreu uma alta mortalidade, e somente $8 \%$ atingiram a fase adulta (Tabela 2). CividanEs e SouzA (2003), estudando M. persicae em diferentes temperaturas, observaram que a temperatura de modo geral influenciou a viabilidade dos estádios de M. persicae, principalmente as temperaturas mais elevadas.

A mortalidade foi de $100 \%$, à temperatura de $30{ }^{\circ} \mathrm{C}$, sugerindo que as ninfas dessa espécie não são adaptadas a essa temperatura. O mesmo resultado foi observado por BARLOW (1962), em que $100 \%$ das ninfas de $M$. persicae morreram sob temperatura de $30{ }^{\circ} \mathrm{C}$, tendo como substrato folhas de batata.

Considerando que as cultivares comerciais de berinjela desenvolvem-se melhor na faixa compreendida entre as temperaturas de 18 e $30^{\circ} \mathrm{C}$, e que para o desenvolvimento ninfal de $M$. persicae as temperaturas de 15 e $20^{\circ} \mathrm{C}$ são as ideais nesta cultura, torna-se necessário o monitoramento mais intenso das plantas de berinjela nessa faixa de temperatura, visando à adoção de estratégias de controle. 


\section{CONCLUSÕES}

1. Dentro do intervalo de temperatura estudado, o desenvolvimento ninfal de $M$. persicae sobre discos de folhas de berinjela é favorecido na faixa de 15 e $20^{\circ} \mathrm{C}$.

2. Nas temperaturas de 15 e $20^{\circ} \mathrm{C}$, em algumas ninfas de $M$. persicae ocorreram cincos estádios ninfais.

\section{AGRADECIMENTO}

Os autores agradecem ao Prof. Dr. Francisco Jorge Cividanes, pela cooperação na análise dos dados.

\section{REFERÊNCIAS}

BARLOW, C.A. The influence of temperature on the growth of experimental populations of Myzus persicae (Sulzer) and Macrosiphum euphorbiae (Thomas) (Aphididae). Canadian Journal of Zoology, Ottawa, v.40, p.145-156, 1962.

BASTOS, C.S.; PICANÇO, M.C.; LEITE, G.L.D.; ARAÚJO, J.M. Tabelas de fertilidade e esperança de vida de Myzus persicae (Sulzer) (Homoptera: Aphididae) em couve comum. Científica, São Paulo, v.24, n.1, p.187-197, 1996.

BLACKMAN, R.L.; EASTOP, V.F. Aphids on the world's crops: an identification guide. Chichester: J. Wiley, 1984, 466p.

CEASA. Padronização: Berinjela [on line]. Disponível em: h t t p : / / w w w . c e a s a c a m p i n a s. c o m . b r / padronização_berinjela.htm. Acesso em 13 set. 2004.

CIVIDANES, F.J.; SOUZA V.P. Exigências térmicas e tabelas de vida de fertilidade de Myzus persicae (Sulzer) (Hemiptera: Aphididae) em laboratório. Neotropical Entomology, Londrina, v.32, n.3, p. 413-419, 2003.
DIXON, A.F.G. Parthenogenetic reproduction and the rate of increase in aphids. In: MINKS, A.K.; HARREWINJN, P. World crop pests - aphids: their biology, natural enemies and control. Amsterdam: Elsevier, 1987. v.2A, cap.4.5, p.197-287.

EASTOP, V.F. World wide importance of aphid as virus vector. In: HARRIS, K.F.; MARAMOROSCH, K. (Ed.). Aphids as virus vector. New York: Academic Press, 1977. p.4-47.

EBERT, T.A.; CARTWRIGHT, B. Biology and ecology of Aphis gossypii Glover (Homoptera: Aphididae). Southwestern Entomologist, Dallas, v.22, n.1, p.116-153, 1997.

FILGUEIRA, F.A.R. Solanáceas: III. Pimentão e outras hortaliças fruto. IN: FILGUEIRA, F.A.R. Novo manual de olericultura. Viçosa: UFV, 2002. cap.14, p.242-245.

ILHARCO, F.A. Equilíbrio biológico dos afídeos. Lisboa: Fundação Caloustre Gulbenvian, 1992. 302p.

NARVÁEZ, Z.; NOTZ, A. Desarrollo, longevidad y reproduccion del afido verde del ajonjoli, Myzus persicae (Sulzer) (Homoptera: Aphididae) sobre plantas de papa (Solanum tuberosum L.) y ajonjoli (Sesamum indicum L.). Boletín Entomología Venezolana, Maracay, v.8, n.1, p.53-61, 1993.

PINTO, C.M.F.; MONTEIRO, A.J.A.; COSTA, H.; ZAMBOLIM, L.; DE PAULA JUNIOR, T.Z. Doenças de berinjela e jiló. IN: ZAMBOLIM, L.; VALE, F.X.R.; COSTA, H. Controle de doenças de plantas e hortaliças. Viçosa: Universidade Federal de Viçosa, 2000. v.1, cap.10, p.303-333.

RADCLIFFE, E.B. Insect pests of potato. Annual Reviews of Entomology, Palo Alto, v.27, p.173-204, 1982.

TAMAKI, G.; ANNIS, B.; FOX, L.; GUPTA R.K.; MESZLENY, A. Comparison of yellow holocyclic and green anholocyclic strains of Myzus persicae (Sulzer): low temperature adaptability. Environmental Entomology, Lanham, v.11, n.1, p.231233, 1982.

WALE, M.; BEKELE, J.; EMIRU, S. Biology of the pea aphid, Acyrthosiphon pisum (Harris) (Homoptera: Aphididae) on coolseason legumes. Journal of Insect Science and Its Application, Nairobi, v.20, n.3, p.171-180, 2000.

WILSON, L.T.; BARNETT, W.W. Degree-days: an aid in crop and pest management. California Agriculture, Oakland, v.37, n.1/2, p.4-7, 1983 . 